03,19

\title{
Морфология и термоэлектрические свойства керамики твердых растворов $\gamma-\mathrm{Gd}_{x} \mathrm{Dy}_{1-x} \mathrm{~S}_{1.5-y}$
}

\author{
(C) A.В. Сотников ${ }^{1}$, В.В. Баковец ${ }^{1}$, Michihiro $\mathrm{Ohta}^{2}$, А.Ш. Агажанов ${ }^{3}$, С.В. Станкус ${ }^{3}$ \\ ${ }^{1}$ Институт неорганической химии им. А.В. Николаева СО РАН, \\ Новосибирск, Россия \\ ${ }^{2}$ Research Institute for Energy Conservation, National Institute of Advanced Industrial Science and Technology (AIST), \\ 1-1-1 Umezono, Tsukuba, Ibaraki 305-8568, Japan \\ ${ }^{3}$ Институт теплофизики им. С.С. Кутателадзе СО РАН, \\ Новосибирск, Россия \\ E-mail: sotnikov@niic.nsc.ru
}

Поступила в Редакцию 12 ноября 2019 г.

В окончательной редакции 12 ноября 2019 г.

Принята к публикации 25 ноября 2019 г.

\begin{abstract}
Изучены температурные зависимости коэффициента Зеебека, электропроводности $(T=300-873 \mathrm{~K})$, а также коэффициента теплопроводности и термоэлектрической добротности $(T=300-770 \mathrm{~K})$ поликристаллических образцов твердых растворов на основе сульфидов гадолиния и диспрозия составов $\gamma-\mathrm{Gd}_{x} \mathrm{Dy}_{1-x} \mathrm{~S}_{1.49}$ $(x=0.1,0.2,0.3,0.4)$. Установлено, что морфологические особенности образцов, а именно, удельная площадь поверхности кристаллитов, вызывающая изменение числа деформационных центров определяет величину теплопроводности твердых растворов $\gamma-\mathrm{Gd}_{x} \mathrm{Dy}_{1-x} \mathrm{~S}_{1.49}$, причем установлено наличие аномального снижения теплопроводности для состава $x=0.2$. Для этого состава получены наименьшие значения коэффициента Зеебека $-371 \mu \mathrm{V} / \mathrm{K}$ при $873 \mathrm{~K}$, удельного сопротивления $880 \mu \Omega \cdot \mathrm{m}$ при $873 \mathrm{~K}$ и коэффициента теплопроводности $0.68 \pm 0.03 \mathrm{~W} / \mathrm{m} \cdot \mathrm{K}$ при $770 \mathrm{~K}$, при этом термоэлектрическая добротность достигает величины $Z T=0.23$
\end{abstract}

Ключевые слова: сульфиды РЗЭ, твердые растворы, реальная структура, термоэлектрические свойства.

DOI: 10.21883/FTT.2020.04.49116.627

\section{1. Введение}

В связи с огромными запасами тепловых ресурсов в недрах земли и увеличением спроса на потребление электрической, механической и тепловой энергии разработка и оптимизация новых устройств, генерирующих электроэнергию из природного и техногенного тепла, является актуальным решением проблемы энергетического кризиса [1-12] Решение подобных задач осуществимо с помощью эффекта термоэлектричества, использование которого приведет к экономии и аккумулированию мировых запасов электроэнергии.

В последние несколько лет в области материаловедения активно изучаются высокотемпературные термоэлектрические (ТЭ) материалы, демонстрирующие повышенные значения параметра добротности $Z T$, определяющего эффективность термоэлектрического устройства [1,12-14]:

$$
Z T=\frac{S^{2} \sigma T}{\kappa_{\mathrm{tot}}},
$$

где $S$ - коэффициент Зеебека, $\sigma$ - электропроводность, $\kappa_{\text {tot }}$ - общая теплопроводность.

Из уравнения следует, что одной из важнейших задач освоения термоэлектричества является разработка материалов, обеспечивающих низкую теплопроводность $\left(\kappa_{\text {tot }}\right)$ при оптимальной электропроводности $(\sigma)$ и повышенном коэффициенте термоЭДС $(S)$.
Таким требованиям отвечают полупроводниковые соединения, в частности высокотемпературные термоэлектрические материалы на основе сульфидов редкоземельных элементов (РЗЭ) и их твердых растворов. Отличительной особенностью таких соединений является возможность регулирования концентрации структурноравновесных вакансий и осуществления катионных замещений при сохранении структурного типа $\mathrm{Th}_{3} \mathrm{P}_{4}[15-20]$.

Исследование теплофизических свойств полуторного сульфида гадолиния $\gamma-\mathrm{Gd}_{3-x}\left[V_{\mathrm{Gd}}\right]_{x} S_{4} \equiv \mathrm{GdS}_{1.5-y}$ позволило определить состав $(1.5-y \approx 1.485)$, для которого характерно наименьшее значение коэффициента теплопроводности $[15,21]$. Для повышения параметра $Z T$ необходимо продолжать поиск вариантов уменьшения коэффициентов теплопроводности, создавая дополнительные центры рассеяния фононов в материале $[22,23]$.

Необходимо отметить, что на сегодняшний день, в опубликованных работах по сульфидам РЗЭ, отсутствует детальное изучение влияния структурно-равновесной катионной вакансионной системы и других типов дефектов реальной структуры - нульмерных (катионные замещения, а также температурно-равновесные вакансии), одномерных (дислокации) и двумерных (границы кристаллитов и включений), на термоэлектрические свойства. Например, в работе [24] было показано, что введение в сульфид диспрозия $\gamma$-модификации ионов гадолиния позволяет существенно снизить коэффициент теплопро- 
водности за счет дополнительного рассеяния тепла на решетке твердых растворов сульфидов РЗЭ с разными ионными радиусами. Было высказано предположение, что указанная аномалия может быть связана также с влиянием различий парамагнитных свойств ионов $\mathrm{Dy}^{3+}$ и $\mathrm{Gd}^{3+}$. Однако физико-химическая природа этого явления не была полностью раскрыта. Поэтому, принимая во внимание вышесказанное, необходимо установить корреляции между изменением реальной структуры и термоэлектрическими свойствами сульфидов РЗЭ.

Таким образом, цель настоящей работы - детальное изучение природы внутренних нарушений кристаллической структуры и их влияния на термоэлектрические свойства твердых растворов полуторных сульфидов РЗЭ со структурой $\mathrm{Th}_{3} \mathrm{P}_{4}$, а также оптимизация методик получения материалов с повышенной термоэлектрической добротностью.

\section{2. Экспериментальная часть}

В настоящей работе в качестве исходных твердых веществ использованы оксиды редкоземельных элементов $\mathrm{Gd}_{2} \mathrm{O}_{3}$ и $\mathrm{Dy}_{2} \mathrm{O}_{3}$ (чистота 99.99\%), а также роданид аммония $\mathrm{NH}_{4} \mathrm{SCN}$ (ГОСТ 27067-86) в роли сульфидирующего реагента.

Для получения высокооднородных твердых растворов сульфидов РЗЭ, при синтезе соответствующих прекурсоров оксидов РЗЭ, золь-гель-методом [25,26], использовали молекулярные водные растворы нитратов $\mathrm{Gd}\left(\mathrm{NO}_{3}\right)_{3} \cdot 5 \mathrm{H}_{2} \mathrm{O}$ и $\mathrm{Dy}\left(\mathrm{NO}_{3}\right)_{3} \cdot 5 \mathrm{H}_{2} \mathrm{O}$. В качестве осадителя использовали двукратный избыток $1.44 \mathrm{M}$ раствора $\mathrm{NaOH}$. Благодаря распылению растворов исходных реагентов, происходит осаждение гидроксидов в субмикронных участках маточного раствора, что приводит к образованию частиц нанометрового размера [27]. Полученный осадок отмывали, высушивали $(T=323 \mathrm{~K})$ и отжигали на воздухе $(T=873-1173 \mathrm{~K})$ в течение $2-4 \mathrm{~h}$ до формирования частиц оксидов $\left(\mathrm{Gd}_{x} \mathrm{Dy}_{1-x}\right) \mathrm{O}_{1.5}$ размером $10-20 \mathrm{~nm}$.

Для получения твердых растворов сульфидов РЗЭ применяли твердофазный синтез с использованием порошков твердых растворов оксидов $(\approx 5 \mathrm{~g})$, сульфидирующего реагента - паров роданида аммония, а также газа носителя его паров аргона $\left(V_{\mathrm{gas}}=71 / \mathrm{h}\right)$ [28]. Процесс сульфидирования в зависимости от объектов исследования проводили при $1273 \mathrm{~K}$ и в течение $6-8 \mathrm{~h}$.

Высокотемпературную кубическую модификацию твердых растворов сульфидов РЗЭ $\gamma-\mathrm{Gd}_{x} \mathrm{Dy}_{1-x} \mathrm{~S}_{1.5-y}$ получали отжигом синтезированных сульфидов $\alpha-\mathrm{Gd}_{x} \mathrm{Dy}_{1-x} \mathrm{~S}_{1.5} \quad$ в печи с индукционным нагревом при $T=1473 \mathrm{~K}$ в атмосфере аргона $\left(V_{\text {gas }}=71 / \mathrm{h}\right)$.

Полученные порошки соединений сульфидов $\gamma$-модификации спекали методом горячего прессования в вакууме $\left(P=7 \cdot 10^{-3} \mathrm{~Pa}\right)$ при $1473 \mathrm{~K}$ в течение $2 \mathrm{~h}$. Одноосное давление при формировании плотной керамики составляло $70 \mathrm{MPa}$.
Для получения оптимальных электропроводящих свойств, проводился дополнительный отжиг синтезированной керамики $\gamma-\mathrm{Gd}_{x} \mathrm{Dy}_{1-x} \mathrm{~S}_{1.5-y}$ до достижения заданного отклонения от стехиометрического состава до $\gamma-\mathrm{Gd}_{x} \mathrm{Dy}_{1-x} \mathrm{~S}_{1.49}$. Синтез вели в запаянных ампулах с газопоглотителем избыточной серы и примесного кислорода (порошок металлического лантана) при температуре $1173 \mathrm{~K}$ в течение $48 \mathrm{~h}$. Отклонение состава образцов $\gamma-\mathrm{Gd}_{x} \mathrm{Dy}_{1-x} \mathrm{~S}_{1.5-y}$ определяли методом газовой хроматографии по выделению водорода по реакции сульфида с раствором соляной кислоты [29]. Примесный состав образцов определяли атомно-адсорбционным методом с использованием спектральной установки PGS-2 (Carl Zeiss Jena, Германия) с дугой постоянного тока в качестве источника возбуждения.

Энергодисперсионный химический анализ шлифов керамики проведен на установке Hitachi TM3000 TableTop SEM с приставкой Bruker QUANTAX 70 EDS с картографированием распределения атомов $\mathrm{Gd}$, Dy и $\mathrm{S}$ по поверхности шлифов.

Фазовый состав, а также размер области когерентного рассеяния (CSR) определяли методом порошковой дифрактометрии. Рентгенофазовый анализ осуществлялся на дифрактометре Shimadzu XRD-7000 ( $\mathrm{Cu} K_{\alpha}$-излучение, $\mathrm{Ni}$ фильтр, диапазон $2 \theta 10-80^{\circ}$, шаг $0.03^{\circ}$, накопление $2 \mathrm{~s}$ ).

Для исследования изменений ближнего порядка кристаллической решетки проводили регистрацию КРСспектров образцов на спектрометре LabRAM HR Evolution (Horiba) с возбуждением на $632 \mathrm{~nm}$ (He-Ne лазер) с диаметром пятна $\sim 1-2 \mu \mathrm{m}$ и мощностью $1 \mathrm{~mW}$.

Измерения удельной теплоемкости $\left(C_{p}\right)$ $\gamma-\mathrm{Gd}_{x} \mathrm{Dy}_{1-x} \mathrm{~S}_{1.49}$ проводились на дифференциальном сканирующем калориметре DSC 204 F1 Phoenix фирмы NETZSCH в интервале температур 300-773 K.

Коэффициент температуропроводности $\left(\chi_{T}\right)$ исследуемых образцов определялся методом лазерной вспышки на автоматизированной установке LFA-427 фирмы NETZSCH (Германия) в атмосфере высокочистого аргона (Ar 99.992 vol.\%) в интервале температур 298-973 K. Плоский образец снизу облучается коротким импульсом лазерного излучения $(1.064 \mu \mathrm{m})$. Погрешность измерения коэффициента температуропроводности для твердых образцов составляет $2-5 \%$ в зависимости от температуры. Общий коэффициент теплопроводности $\left(\kappa_{\text {tot }}\right)$ рассчитывался по известному уравнению $\kappa_{\mathrm{tot}}=\chi_{T} \rho_{\mathrm{cer}} C_{p}$, где $\chi_{T}$ - коэффициент температуропроводности, $C_{p}-$ теплоемкость, $\rho_{\text {cer }}$ - плотность керамического материала. Экспериментальные значения $\chi_{T} \mathrm{~T}$, полученные методом лазерной вспышки, содержат решеточную и электронную диффузионную составляющие.

Коэффициент Зеебека и удельное сопротивление прессованных образцов размерами $8 \times 2 \times 4$ измерялись одновременно с использованием установки ZEM-3 (Advance Riko, Japan) в интервале температур 298-873 К. Погрешности определения величин коэффициента Зеебека и удельного сопротивления образцов составляют $\sim 5 \%$. 
$a$

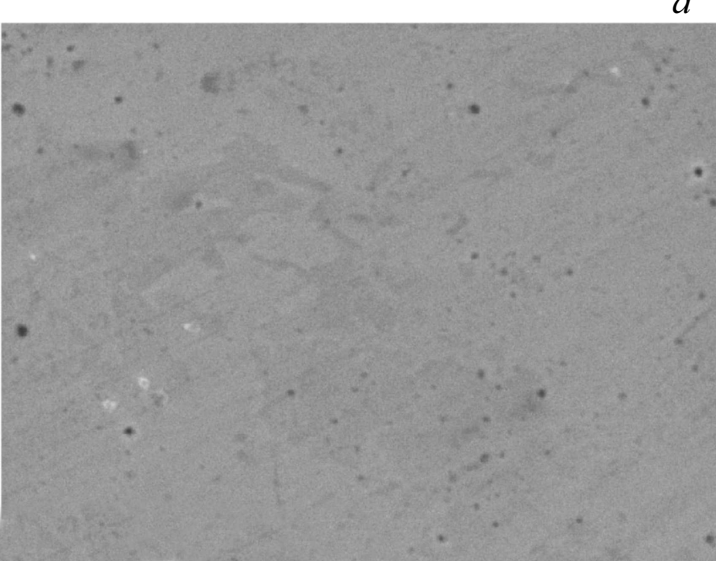

$30 \mu \mathrm{m}$
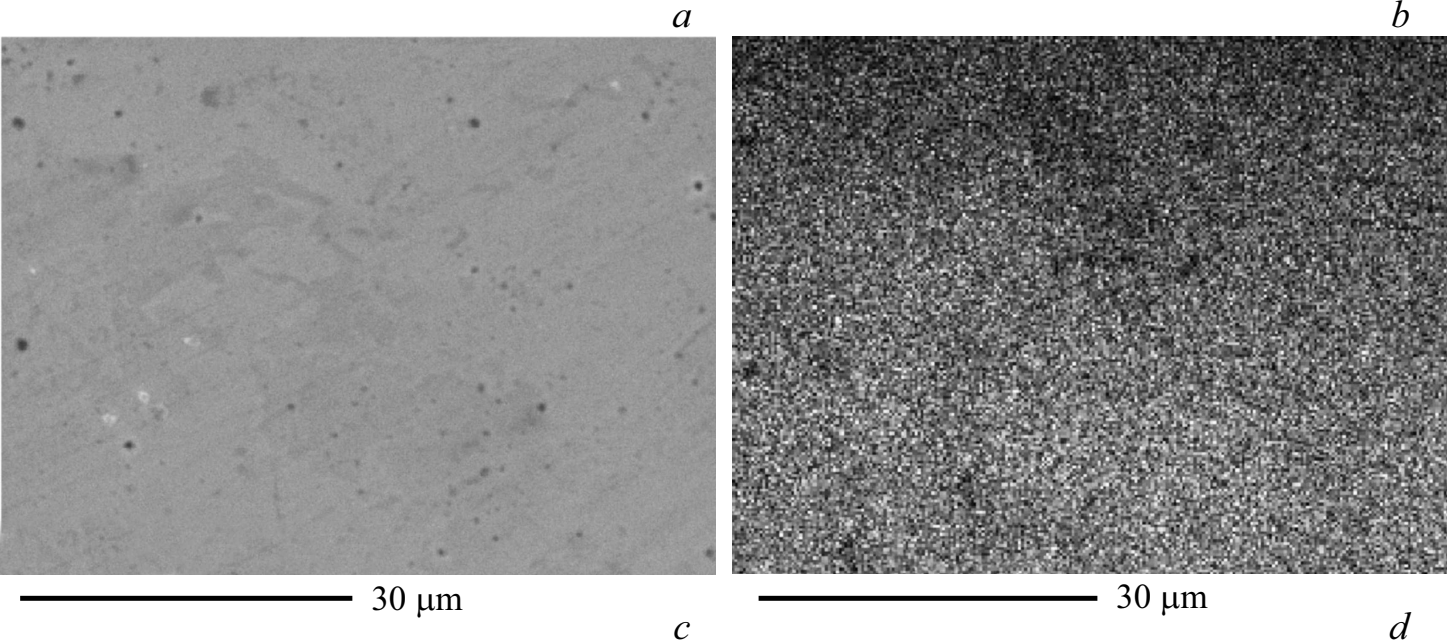

$c$

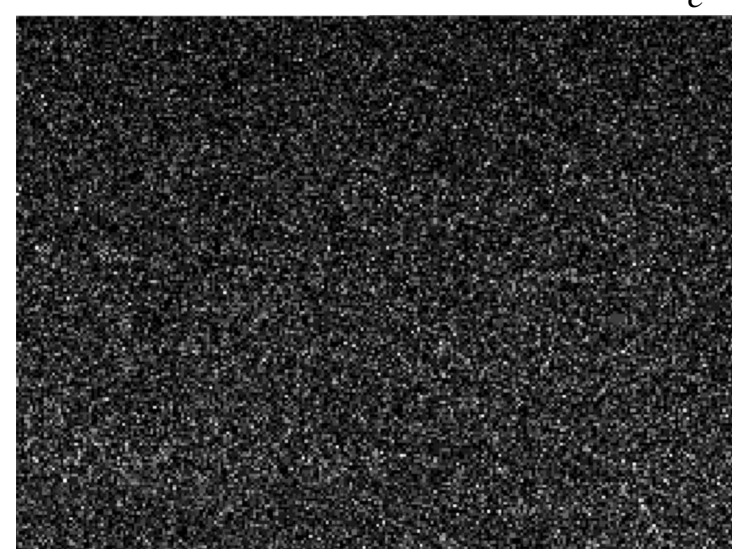

$30 \mu \mathrm{m}$

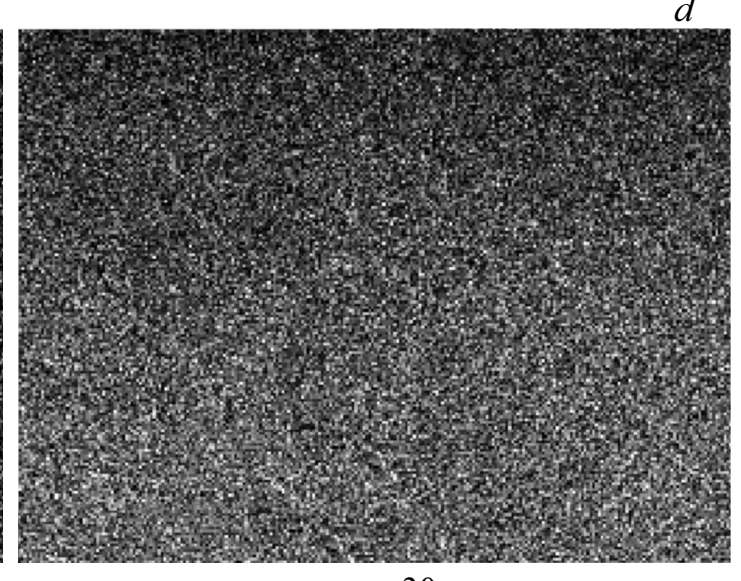

$30 \mu \mathrm{m}$

$30 \mu \mathrm{m}$

Рис. 1. Электронно-микроскопическое изображение $(a)$ и распределение элементов $S(b), \operatorname{Gd}(c)$ и $\mathrm{Dy}(d)$ в керамике состава $\gamma-\mathrm{Gd}_{0.2} \mathrm{Dy}_{0.8} \mathrm{~S}_{1.49}$.

Изучение магнитных свойств соединений было проведено методом Фарадея с использованием крутильных кварцевых весов с электромагнитной стабилизацией. Напряженность магнитного поля при получении температурной зависимости магнитной восприимчивости составляла $7.3 \mathrm{kOe}$, точность стабилизации напряженности поля $\sim 2 \%$.

\section{3. Результаты и обсуждения}

\section{1. Химический состав}

Энергодисперсионный анализ шлифа спеченной керамики подтвердил однородность распределения элементов $\mathrm{Gd}$, Dy и $\mathrm{S}$ в соединениях $\gamma-\mathrm{Gd}_{x} \mathrm{Dy}_{1-x} \mathrm{~S}_{1.49}$ (рис. 1 ).

Результаты проведенного химического спектрального анализа примесного состава исходных оксидов и полученной керамики представлены в табл. 1. Суммарное содержание примесей по 30 элементам $<0.2 \operatorname{mass} \%$, a максимальный уровень отдельных примесных элементов не превышал $8 \cdot 10^{-2}$ mass $\%$.
Таблица 1. Примесный состав исследованных образцов

\begin{tabular}{c|l|l}
\hline Элемент/соединения & $\mathrm{Gd}_{x} \mathrm{Dy}_{1-x} \mathrm{O}_{1.5}$ & $\gamma-\mathrm{Gd}_{x} \mathrm{Dy}_{1-x} \mathrm{~S}_{1.5-y}$ \\
\hline $\mathrm{Ag}, \mathrm{Cu}$ & $<2 \cdot 10^{-3}$ & $<2 \cdot 10^{-3}$ \\
$\mathrm{Al}, \mathrm{Au} \mathrm{Cr}, \mathrm{Fe}, \mathrm{Mo}, \mathrm{Pd}, \mathrm{Sn}, \mathrm{Te}$ & $<0.01$ & $<0.01$ \\
$\mathrm{As}$ & $<0.08$ & $<0.08$ \\
$\mathrm{Ba}, \mathrm{Ca}, \mathrm{Nb}, \mathrm{Pt}, \mathrm{Ta}$ & $<0.03$ & $<0.03$ \\
$\mathrm{Be}, \mathrm{Cd}, \mathrm{Mn}$ & $<5 \cdot 10^{-4}$ & $<5 \cdot 10^{-4}$ \\
$\mathrm{Bi}, \mathrm{Tl}$ & $<5 \cdot 10^{-3}$ & $<5 \cdot 10^{-3}$ \\
$\mathrm{Ga}, \mathrm{Mg}, \mathrm{Ni}, \mathrm{Zn}$ & $<1 \cdot 10^{-3}$ & $<1 \cdot 10^{-3}$ \\
$\mathrm{~V}, \mathrm{~Pb}, \mathrm{Co}, \mathrm{Ge}$ & $<0.02$ & $<0.02$ \\
$\mathrm{Hf}, \mathrm{Ti}, \mathrm{Zr}$ & $<0.05$ & $<0.05$ \\
$\mathrm{In}$ & $<9 \cdot 10^{-3}$ & $<9 \cdot 10^{-3}$ \\
& &
\end{tabular}

\section{2. РФА твердых растворов}

Результаты РФА подтвердили однофазный состав синтезированной керамики твердых растворов сульфидов $\mathrm{Gd}$ и Dy с кубической структурой $\mathrm{Th}_{3} \mathrm{P}_{4}(I 43 d, Z=4)$. По результатам дифрактометрии (рис. 2, $a$ ) рассчитаны параметры ЭЯ решеток исследуемых соединений $\gamma-\mathrm{Gd}_{x} \mathrm{Dy}_{1-x} \mathrm{~S}_{1.49}$ и построена зависимость параметра 


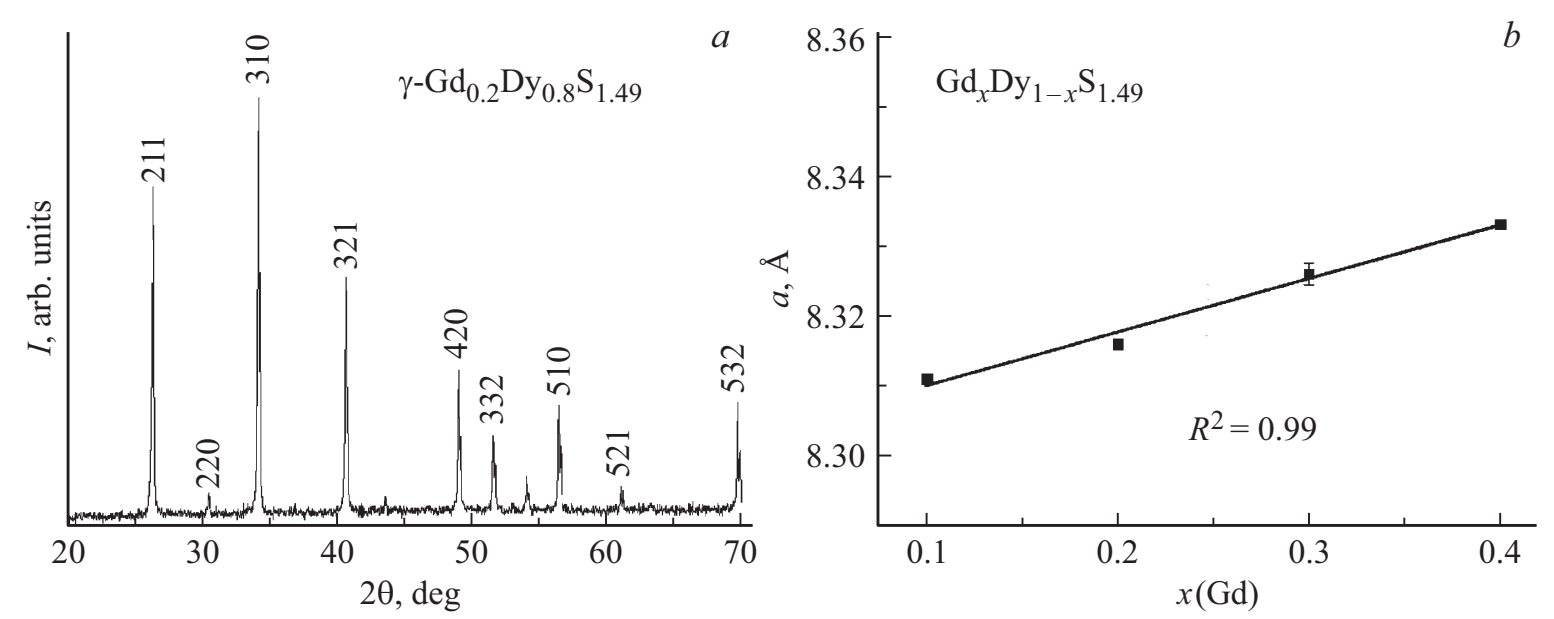

Рис. 2. РФА прессованной керамики $\gamma-\mathrm{Gd}_{0.2} \mathrm{Dy}_{0.8} \mathrm{~S}_{1.49}(a)$ и рассчитанные параметры элементарной ячейки исследуемых твердых растворов сульфидов Gd и Dy $(b)$.

элементарной ячейки а от состава твердого раствора (рис. $2, b)$.

Аппроксимация экспериментальных данных прямой линией с высоким коэффициентом регрессии $\left(R^{2}=0.99\right)$ подтверждает образование твердых растворов в исследуемой области составов (рис. 2, $b$ ).

Оценку кристалличности синтезированных образцов провели, используя средние значения $\mathrm{CSR}_{\mathrm{av}}=$ $=\Sigma \mathrm{CSR}_{\mathrm{ex}} / n_{\mathrm{xrd}}$, где $n_{\mathrm{xrd}}-$ число рефлексов дифрактограммы. Значения $\mathrm{CSR}_{\mathrm{av}}$ рассчитаны по методу ДебаяШеррера и их зависимости от состава исследуемого твердого раствора представлены на рис. 3 .

Полученные зависимости имеют немонотонный характер с минимальным значением $\mathrm{CSR}_{\mathrm{av}}$ при $x=0.2$. Поликристаллическая керамика характеризуется наличием совокупности множества кристаллитов, размеры которых отражены величинами $\mathrm{CSR}_{\mathrm{av}}$. Согласно теории и практике поверхностных явлений, в многокомпонентной по химическому составу поликристаллической системе с развитой поверхностью микро- и наноструктуры отдель-

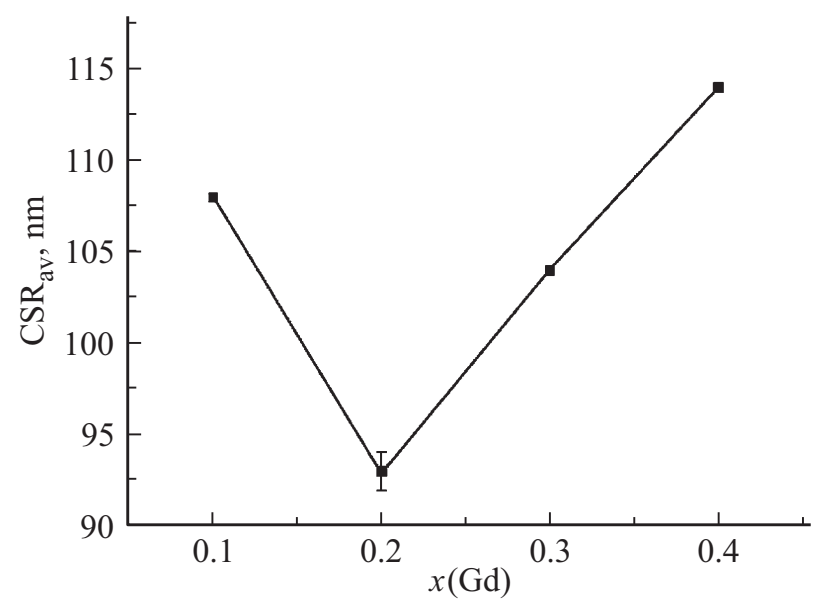

Рис. 3. Изменение $\mathrm{CSR}_{\mathrm{av}}$ от состава твердых растворов $\gamma-\mathrm{Gd}_{x} \mathrm{Dy}_{1-x} \mathrm{~S}_{1.49}$. ные компоненты выступают в качестве поверхностно активных. В данной системе, по-видимому, ионы $\mathrm{Gd}^{3+}$ являются поверхностно-активными в области их концентраций, близких к составу $x=0.2$ и способствуют относительно большой скорости зарождения кристаллитов при формировании твердого раствора. Это, в свою очередь, приводит к повышенной дисперсности образцов.

Известно, что кристаллиты контактируют по полукогерентным границам и вызывают появление дислокаций и деформационных напряжений в смежных областях. Таким образом, обнаруженная немонотонность зависимости $\mathrm{CSR}_{\mathrm{av}}=f(x)$ характеризует изменение удельной площади поверхности границ кристаллитов и деформационных напряжений с максимумом для состава $x=0.2$. Это, как было показано в [21] на примере соединений $\gamma-\mathrm{GdS}_{1.5-y}$, сопровождается изменением ближнего порядка кристаллической решетки, а именно увеличением концентрации деформационных центров $N_{C}$, возникающих на границах раздела кристаллитов. В работе [23] продемонстрировано, что число деформированных узлов решетки или дефектных центров определяется соотношением $N_{C}=2 \cdot 10^{15} S_{\mathrm{sp}}$, где $2 \cdot 10^{15}$ - оценочное число узлов решетки на $1 \mathrm{~cm}^{2}$ и $S_{\mathrm{sp}}-$ удельная площадь кристаллитов на $1 \mathrm{~cm}^{3}$. Результаты расчетов параметра $N_{C}$ для соединений $\gamma-\mathrm{Gd}_{x} \mathrm{Dy}_{1-x} \mathrm{~S}_{1.49}$ представлены в табл. 2.

Полуторные сульфиды Р3Э кубической модификации $\gamma-\mathrm{LnS}_{1.5-y}$ характеризуются развитой струк-

Таблица 2. Число деформационных центров в области границ кристаллитов

\begin{tabular}{c|c}
\hline Соединение & $N_{C}, 10^{21} \mathrm{~cm}^{-3}$ \\
\hline$\gamma-\mathrm{Gd}_{0.1} \mathrm{Dy}_{0.9} \mathrm{~S}_{1.49}$ & 1.10 \\
$\gamma-\mathrm{Gd}_{0.2} \mathrm{Dy}_{0.8} \mathrm{~S}_{1.49}$ & 1.28 \\
$\gamma-\mathrm{Gd}_{0.3} \mathrm{Dy}_{0.7} \mathrm{~S}_{1.49}$ & 1.16 \\
$\gamma-\mathrm{Gd}_{0.4} \mathrm{Dy}_{0.6} \mathrm{~S}_{1.49}$ & 1.04
\end{tabular}



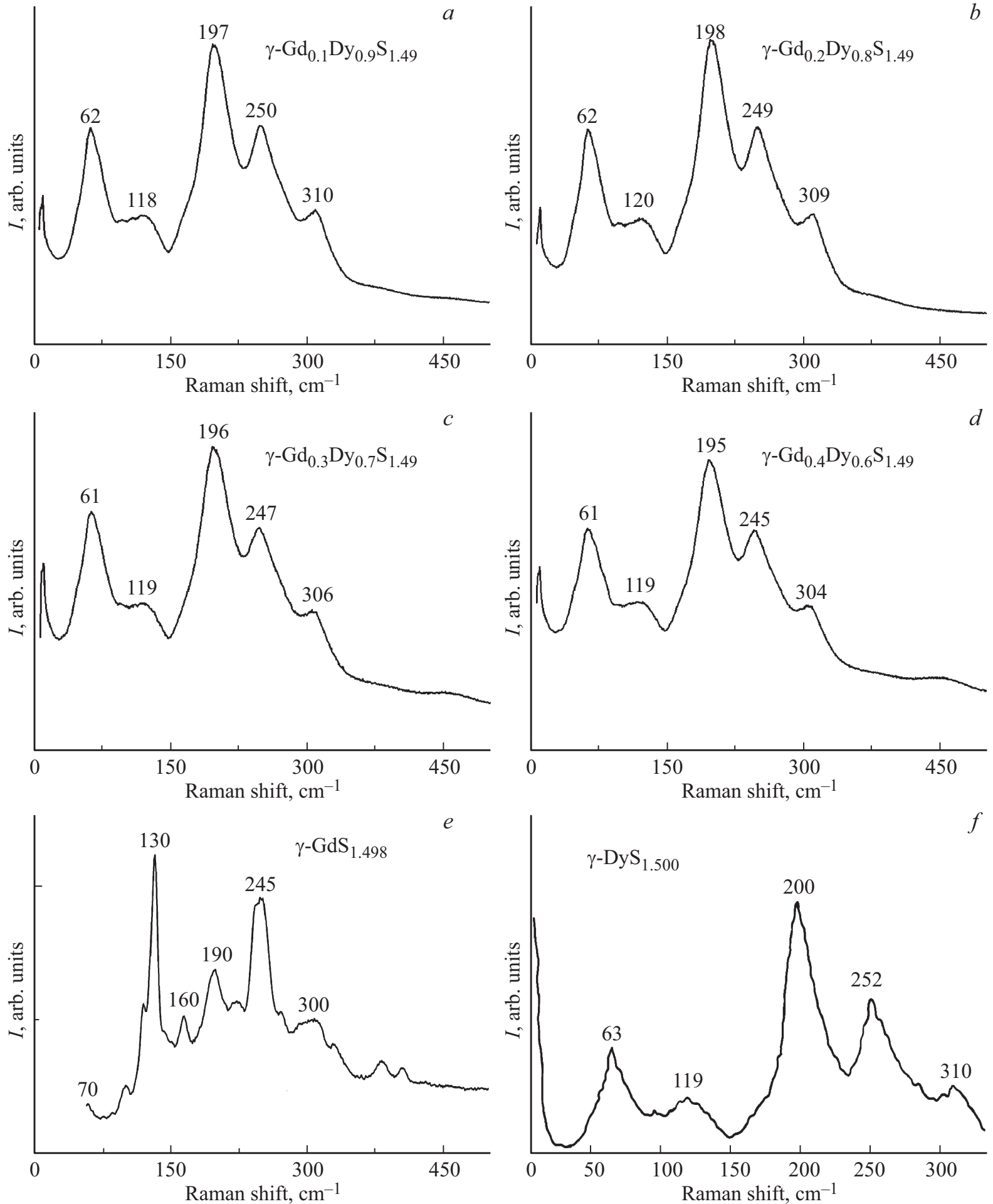

Рис. 4. КРС-спектры исследуемых твердых растворов $\gamma-\mathrm{Gd}_{x} \mathrm{Dy}_{1-x} \mathrm{~S}_{1.49}(a-d)$ и соединений $\gamma$-GdS $\mathrm{G}_{1.498}(e), \gamma$-DyS $\mathrm{S}_{1.500}(f)$.

турно равновесной вакансионной системой с концентрацией вакансий для $y=1.479-1.498$, равной $(5.3-5.9) \cdot 10^{21} \mathrm{~cm}^{-3}[21]$. Однако у нас нет оснований рассматривать изменение этой величины с изменением состава твердого раствора $x$.

Для дальнейшего анализа изменений ближнего порядка использовали КРС-спектроскопию.

\section{3. КРС-спектроскопия твердых растворов}

На рис. 4 представлены КРС-спектры порошков $\gamma-\mathrm{Gd}_{x} \mathrm{Dy}_{1-x} \mathrm{~S}_{1.49}$, где $x=0.1,0.2,0.3,0.4$ и соединений $\gamma-\mathrm{GdS}_{1.498}, \gamma-\mathrm{DyS}_{1.500}$.

В исследованном диапазоне спектра наблюдаются мода $195 \mathrm{~cm}^{-1}\left(A_{1}\right)$ и две моды $\approx 60,305 \mathrm{~cm}^{-1}(E)$ 


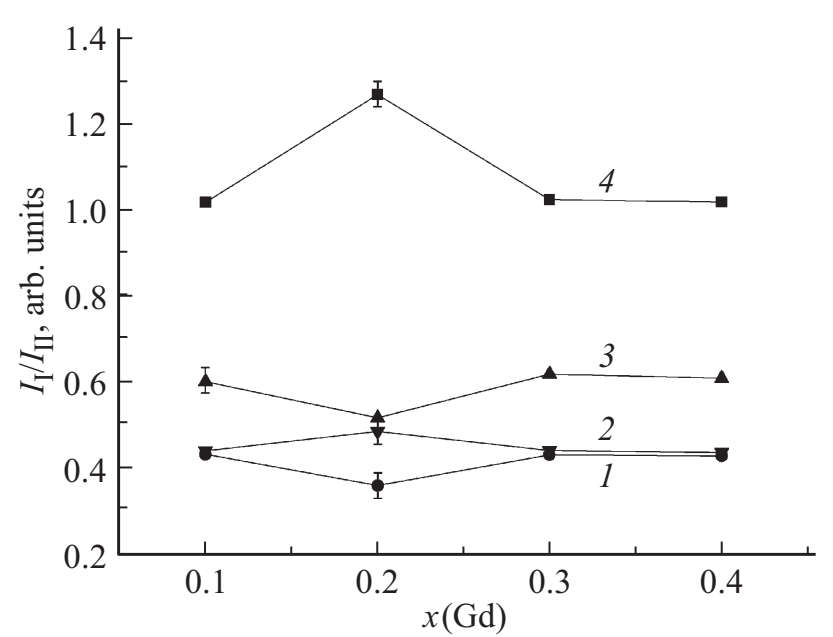

Рис. 5. Изменение отношений интенсивностей мод $I_{\mathrm{I}} / I_{\mathrm{II}}$ : $1-120 / 195,2-60 / 195,3-120 / 245,4-60 / 120 \mathrm{~cm}^{-1}$ КРС-спектров.

и $\approx 245,160 \mathrm{~cm}^{-1}\left(F_{2}\right)$. Обнаруженные полосы КРСспектров можно приписать к колебаниям определенных атомных групп. Для этого воспользуемся полученным в работе [23] КРС-спектром соединения $\gamma$ - $\mathrm{GdS}_{1.498}$ и литературными данными для $\gamma$-DyS $\mathrm{S}_{1.500}$ [30]. Движению катионов $\mathrm{Dy}^{3+}$ соответствует мода $60 \mathrm{~cm}^{-1}$, для катионов $\mathrm{Gd}^{3+}$ это полоса $70 \mathrm{~cm}^{-1}$, а для анионов $S^{2}$-полосы 195, 245 и $305 \mathrm{~cm}^{-1}$. Полосу $120 \mathrm{~cm}^{-1}$ следует отнести к суперпозиции колебаний $\mathrm{Dy}^{3+}$ и $\mathrm{Gd}^{3+}$ $\left(119 \mathrm{~cm}^{-1}\right.$ для $\mathrm{Dy}^{3+}$ и $130 \mathrm{~cm}^{-1}$ для $\left.\mathrm{Gd}^{3+}\right)$. В исследуемых твердых растворах позиции катионов РЗЭ $($ КЧ $=8)$ можно представить в следующих окружениях (с КЧ $=7$ для ионов $\mathrm{S}^{2-}$ ): (Dy-S $)_{7}$-Gd-(S-Dy) - I, $(\text { Dy-S })_{6}-(\mathrm{Gd}-\mathrm{S})-\mathrm{Dy}-(\mathbf{S}-\mathrm{Dy})$ - II, (Dy-S $)_{7}-\mathrm{Gd}-\left(\mathbf{S}-V_{\text {Dy }}\right)-$ III, $(\text { Dy-S })_{6}-(\mathrm{Gd}-\mathrm{S})-\mathrm{Dy}-\left(\mathbf{S}-V_{\text {Dy }}\right)-\mathrm{IV},(\mathrm{Dy}-\mathrm{S})_{7}-\mathrm{Gd}-\left(\mathbf{S}-V_{C}\right)-\mathrm{V}$ и $(\mathrm{Dy}-\mathrm{S})_{6}-(\mathrm{Gd}-\mathrm{S})-\mathrm{Dy}-\left(\mathrm{S}-V_{C}\right)-\mathrm{VI}$, где $V_{\mathrm{Dy}}-$ вакансии диспрозия, $V_{C}$ - центры деформированных катионных узлов связанных с реальной структурой полукогерентных границ кристаллитов. Полужирным шрифтом обозначены атомы $\mathbf{S}$, движению которых приписаны полосы КРС-спектров. Понятно, что возможно существование окружений типа (Dy-S $)_{5}-(\mathrm{Gd}-\mathrm{S})-(\mathrm{Dy}-\mathrm{S})-\mathrm{Dy}-(\mathbf{S}-X)$ и $(\text { Dy-S })_{4}-(\mathrm{Gd}-\mathrm{S})-(\mathrm{Dy}-\mathrm{S})_{2}$-Dy-(S-X) в соединениях с высокой концентрацией ионов $\mathrm{Dy}^{3+}$, где $X=\mathrm{Dy}, V_{\mathrm{Dy}}, V_{C}$. Принимая во внимание статистическое распределение ионов РЗЭ в решетке типа $\mathrm{Th}_{3} \mathrm{P}_{4}$ [31], эти позиции приняты близкими к позициям II, IV и VI.

Установлено, что частичное замещение ионов $\mathrm{Dy}^{3+}$ ионами $\mathrm{Gd}^{3+}$ не приводит к изменению относительной интенсивности колебательных мод 195, 245 и $305 \mathrm{~cm}^{-1}$, однако их положение сдвигается в направлении от Dy к $\mathrm{Gd}$ (в сторону уменьшения содержания диспрозия). Bce обнаруженные особенности согласуются с ранее полученными КРС-спектрами для индивидуальных полуторных сульфидов Dy и Gd $[30,32]$. Поскольку группы I и II имеют наиболее высокие симметрию и концентрации, соответствующие моды $245 \mathrm{~cm}^{-1}\left(F_{2}\right)$ и $300 \mathrm{~cm}^{-1}(E)$ должны быть похожи для всех образцов, что и наблюдается на представленных КРС-спектрах (рис. $4, a-d$ ). Полосу $160 \mathrm{~cm}^{-1}$, которая имеет очень малую интенсивность и проявляется изгибом на полосе $195 \mathrm{~cm}^{-1}$ в спектрах соединений $\gamma-\mathrm{Gd}_{x} \mathrm{Dy}_{1-x} \mathrm{~S}_{1.49}$, следует отнести к группам III и IV, так как их концентрация мала. В свою очередь, группам V и VI можно приписать полосу 195-198 $\mathrm{cm}^{-1}$, так как максимум полос сдвигается в сторону увеличения $x \mathrm{Gd}$. На рис. 5 представлены изменения отношений интенсивностей мод $\left(I_{\mathrm{I}} / I_{\mathrm{II}}\right)$ групп I и II в каждом спектре. Аномалии зависимостей $I_{\mathrm{I}} / I_{\mathrm{II}}=f(x)$ для соединения $\gamma-\mathrm{Gd}_{0.2} \mathrm{Dy}_{0.8} \mathrm{~S}_{1.49}$ указывают на перестройку ближнего порядка кристаллической решетки.

Полученные особенности изменений отношений $I_{\mathrm{I}} / I_{\mathrm{II}}$ полос КРС-спектров коррелируют с изменением величин $\operatorname{CSR}_{\mathrm{av}}$ (рис. 3) и, следовательно, непосредственно связаны с изменением концентрации деформационных центров на границах раздела кристаллитов. Это, в свою очередь, должно проявиться в характере изменения величины коэффициента теплопроводности с изменением концентрации $x \mathrm{Gd}$.

\section{4. Термоэлектрические свойства твердых растворов}

На рис. 6 представлены температурные зависимости температуропроводности $\chi_{T}$ и теплоемкости $C_{p}$, а также основные термоэлектрические параметры: коэффициента Зеебека $S$, удельного сопротивления $\rho$, фактора мощности $S^{2} / \rho$ и общего $\kappa_{\text {tot }}$ коэффициента теплопроводности и термоэлектрической добротности ZT для соединений $\gamma-\mathrm{Gd}_{x} \mathrm{Dy}_{1-x} \mathrm{~S}_{1.49}$, где $x=0.1,0.2,0.3,0.4$.

Измеренные плотности керамических образцов: $D\left(\gamma-\mathrm{Gd}_{0.1} \mathrm{Dy}_{0.9} \mathrm{~S}_{1.49}\right)=6.198 \mathrm{~g} / \mathrm{cm}^{3}, D\left(\gamma-\mathrm{Gd}_{0.2} \mathrm{Dy}_{0.8} \mathrm{~S}_{1.49}\right)=$ $=6.184 \mathrm{~g} / \mathrm{cm}^{3}, \quad D\left(\gamma-\mathrm{Gd}_{0.3} \mathrm{Dy}_{0.7} \mathrm{~S}_{1.49}\right)=6.183 \mathrm{~g} / \mathrm{cm}^{3}$, $D\left(\gamma-\mathrm{Gd}_{0.4} \mathrm{Dy}_{0.6} \mathrm{~S}_{1.49}\right)=6.193 \mathrm{~g} / \mathrm{cm}^{3}$ (погрешность $\left.2 \%\right)$. Отрицательный знак коэффициента Зеебека и рост величины удельного сопротивления с увеличением температуры указывает на то, что полученные соединения являются вырожденными полупроводниками с электронным типом проводимости (n-тип). В общем случае $\kappa_{\text {tot }}=\kappa_{\text {lat }}+\kappa_{\text {el }}$, где $\kappa_{\text {lat }}$ и $\kappa_{\mathrm{el}}-$ решеточная и электронная составляющие теплопроводности. Вклад электронной составляющей очень мал, поскольку для исследуемых образцов получены высокие значения удельного сопротивления (низкая концентрация носителей заряда). Таким образом теплопроводность исследуемых соединений в основном определяется решеточной составляющей.

Анализ результатов не подтвердил предположение [24] о влиянии различий парамагнитных свойств ионов $\mathrm{Dy}^{3+}$ и $\mathrm{Gd}^{3+}$ на возникновение аномалий теплопроводности твердого раствора состава $\gamma-\mathrm{Gd}_{0.2} \mathrm{Dy}_{0.8} \mathrm{~S}_{1.49}$, так как не было выявлено аномалий изменения магнитной восприимчивости с изменением состава рассматриваемого ряда твердых растворов. 

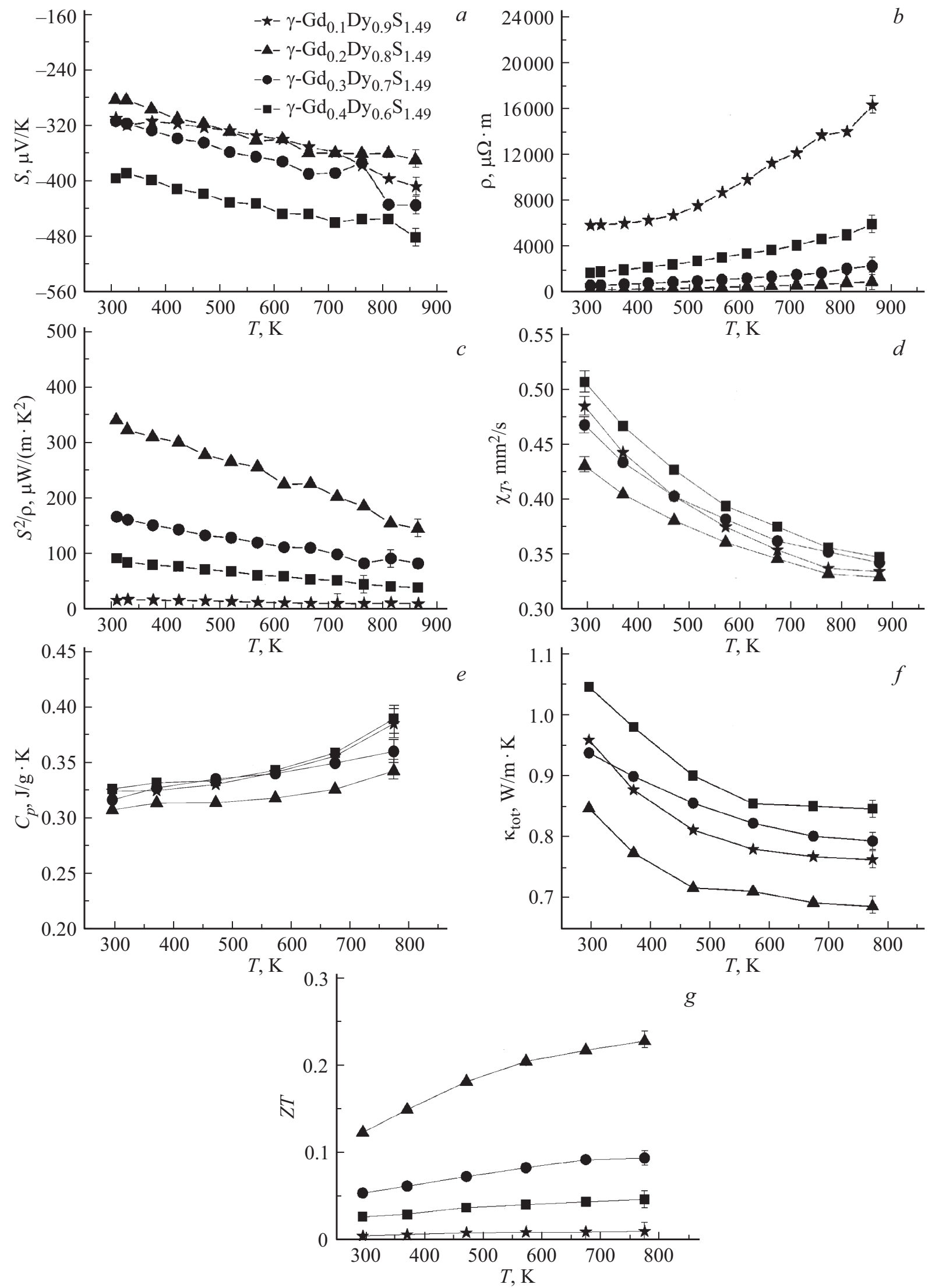

Рис. 6. Температурные зависимости термоэлектрических свойств температуропроводности и теплоемкости исследуемых твердых растворов $\gamma-\mathrm{Gd}_{x} \mathrm{Dy}_{1-x} \mathrm{~S}_{1.49}: S(a), \rho(b), S^{2} / \rho(c), C_{p}(d), \chi_{T}(e), \kappa_{\mathrm{tot}}(f)$ и термоэлектрической добротности $Z T(g)$. 

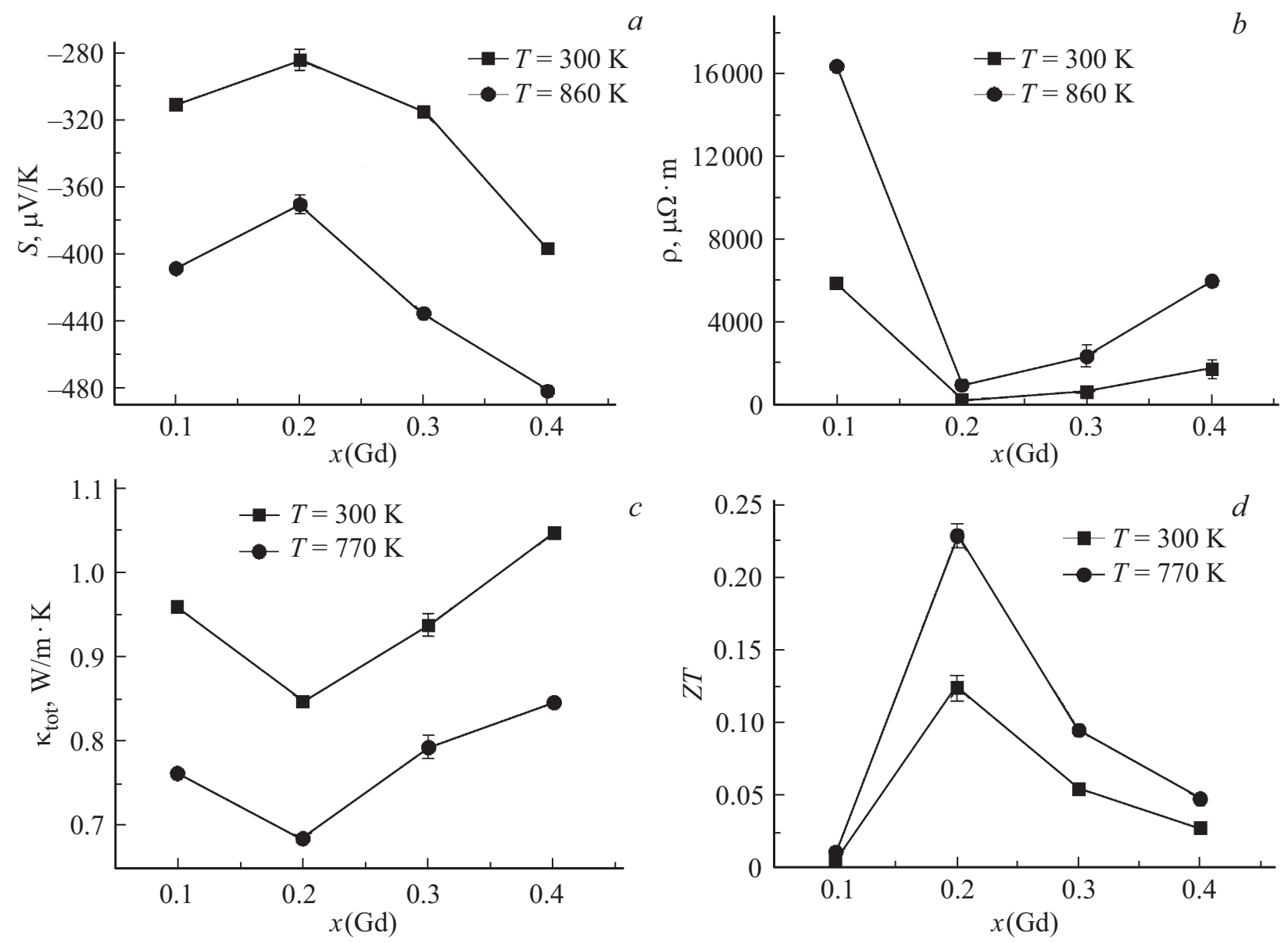

Рис. 7. Зависимости термоэлектрических параметров и добротности $Z T$ от состава твердого раствора $\gamma-\mathrm{Gd}_{x} \mathrm{Dy}_{1-x} \mathrm{~S}_{1.49}$.

Результаты измерений показали, что для соединения $\gamma-\mathrm{Gd}_{0.2} \mathrm{Dy}_{0.8} \mathrm{~S}_{1.49}$ получены наименьшие величины коэффициентов Зеебека и теплопроводности и также удельного сопротивления. В соответствии с уравнением (1) термоэлектрическая добротность для данного состава максимальна и при $T=770 \mathrm{~K}$ достигает величины 0.23 (рис. 6,g). Верхний предел температуры $770 \mathrm{~K}$ принят, так как измерение $\kappa_{\text {tot }}$ не проведено выше этой величины.

На рис. 7 представлены зависимости термоэлектрических параметров от состава твердого раствора.

Полученные зависимости изменяются немонотонно с резким изменением величин термоэлектрических параметров $S, \kappa_{\text {tot }}$ и $\rho$ для твердого раствора состава $\gamma-\mathrm{Gd}_{0.2} \mathrm{Dy}_{0.8} \mathrm{~S}_{1.49}$. В свою очередь, эти аномалии коррелируют с особенностями внутренних морфологических изменений керамики соответствующих соединений, что подтверждается установленными аномалиями изменений величин $\mathrm{CSR}_{\mathrm{av}}$. Следовательно, изменение дефектности решетки твердых растворов $\left(\mathrm{Gd}_{x} \mathrm{Dy}_{1-x}\right) \mathrm{S}_{1.49}$, вызванное изменением внутренней микроструктуры, является основной причиной аномалий термоэлектрических параметров для состава $x(\mathrm{Gd})=0.2$. Для этого состава достигнуто минимальное значение коэффициента теплопроводности $0.68 \pm 0.03 . \mathrm{W} /(\mathrm{m} \cdot \mathrm{K})$ при $770 \mathrm{~K}$, что меньше, чем аналогичный показатель для известного соединения состава $\mathrm{GdS}_{1.487}(0.74 \pm 0.04 \mathrm{~W} / \mathrm{m} \cdot \mathrm{K})$ [21]. Уменьшение удельного сопротивления при этом составе также может быть следствием увеличения удельной площади поверхности и связанной с ней повышенной дефектностью приграничной области кристаллитов, например, с присутствием дислокаций и деформационных центров решетки на границах кристаллитов. Это, в свою очередь, может отражаться на повышении проводимости за счет поверхностных электронных состояний.

Значение термоэлектрической добротности для твердого раствора состава $\gamma-\mathrm{Gd}_{0.2} \mathrm{Dy}_{0.8} \mathrm{~S}_{1.49}$ при $T=770 \mathrm{~K}$ составляет 0.23 (рис. 7,d), что на более чем $60 \%$ выше соответствующих значений для других составов твердого раствора. Это связано в частности с аномальным понижением теплопроводности материала при $x=0.2$. Можно полагать, что параметр $Z T$ может быть еще увеличен для соединения $\gamma-\mathrm{Gd}_{0.2} \mathrm{Dy}_{0.8} \mathrm{~S}_{1.5-y}$, за счет уменьшения концентрации структурно-равновесных катионных вакансий до состава $y=0.022$, так как электропроводность при этом достигает больших значений $[33,34]$. Кроме того, для повышения добротности $Z T$ твердых растворов целесообразно использовать 
Р3Э с большей разницей радиусов ионов, что должно снизить теплопроводность за счет усложнения спектра фононов.

\section{4. Заключение}

Керамические образцы твердых растворов на основе сульфидов гадолиния и диспрозия составов $\gamma-\mathrm{Gd}_{x} \mathrm{Dy}_{1-x} \mathrm{~S}_{1.49}(x=0.1,0.2,0.3,0.4)$ являются информативными объектами для рассмотрения реальной структуры различной размерности и механизмов ее влияния на термоэлектрические свойства соответствующих материалов. Для состава $\gamma-\mathrm{Gd}_{0.2} \mathrm{Dy}_{0.8} \mathrm{~S}_{1.49}$ термоэлектрические параметры образцов $S, \rho$ и $\kappa_{\text {tot }}$ имеют аномально низкие значения: $-370 \mu \mathrm{V} / \mathrm{K} \quad(T=860 \mathrm{~K})$, $700 \mu \Omega \cdot \mathrm{m} \quad(T=860 \mathrm{~K})$ и $0.68 \mathrm{~W} /(\mathrm{m} \cdot \mathrm{K}) \quad(T=770 \mathrm{~K})$ соответственно. Эти аномалии связаны с максимально высокой удельной площадью границ кристаллитов и связанной с ней концентрацией деформационных центров кристаллической решетки. Это приводит к усложнению фононного спектра, изменению поверхностных состояний носителей зарядов и их транспортных свойств.

Изменения реальной структуры твердых растворов сульфидов, в частности, определяются различиями ионных радиусов катионов $\mathrm{Gd}^{3+}$ и $\mathrm{Dy}^{3+}$ и их концентрациями. Это приводит к значительным нарушениям дальнего и ближнего порядков решетки, вызывающих понижение теплопроводности за счет уменьшения длины свободного пробега фононов.

Для указанного состава твердых растворов термоэлектрическая добротность $Z T$ при $770 \mathrm{~K}$ имеет максимальное значение 0.23 . Перспективным путем увеличения $Z T$ в дальнейшем является использование РЗЭ катионов с большей разницей ионных радиусов для формирования твердых растворов. Для повышения электропроводности и оптимизации коэффициента Зеебека твердых растворов сульфидов РЗЭ кубической модификации необходимо увеличивать отклонение от стехиометрического состава соединений по сере до $y=0.022$ или легировать соединения соответствующими элементами, обеспечивающими повышенное содержание свободных носителей зарядов. В этом отношении твердые растворы сульфидов РЗЭ имеют определенную техническую перспективность, так как эти соединения позволяют получать материалы с $p$ - и $n$-типами проводимости. Это необходимо для создания высокотемпературной термоэлектрической пары для технических устройств с использованием материалов, синтезированных из одних и тех же химических элементов РЗЭ и серы.

\section{Благодарности}

Авторы статьи выражают благодарность Д.П. Пищуру, N. Fujimoto за проведение измерений термоэлектрических свойств, Е.В. Коротаеву за проведение измерений магнитных свойств и И.Ю. Филатовой и за помощь при синтезе твердых растворов сульфидов РЗЭ.

\section{Финансирование работы}

Работа выполнена в рамках государственного задания ИНХ СО РАН в области фундаментальных научных исследований. Измерения коэффициента температуропроводности выполнены в рамках государственного задания ИТ СО РАН (АААА-А17-117022850029-9).

\section{Конфликт интересов}

Авторы заявляют, что у них нет конфликта интересов.

\section{Список литературы}

[1] J. He, M.G. Kanatzidis, V.P. Dravid. Mater. Today 16, 166 (2013).

[2] D.K. Aswal, R. Basu, A. Singh. Energy Convers. Manag. 114, 50 (2016).

[3] T.M. Tritt, H. Bottner, L. Chen. MRS Bull. 33, 366 (2008).

[4] W. Liu, Q. Jie, H.S. Kim, Z. Ren. Acta Mater. 87, 357 (2008).

[5] M. Zebarjadi, K. Esfarjani, M.S. Dresselhaus, Z.F. Ren, G. Chen. Energy Environ. Sci. 5, 5147 (2012).

[6] L.E. Bell. Science 321, 1457 (2008).

[7] J.R. Sootsman, D.Y. Chung, M.G. Kanatzidis. Angew. Chem. Int. Ed. 48, 8616 (2009).

[8] G.J. Snyder, E.S. Toberer. Nature Mater. 7, 105 (2008).

[9] А.В. Шевельков. Успехи химии 77, 3 (2008).

[10] R. Zevenhoven, A. Beyene. Energy 36, 3754 (2011).

[11] J. Yang, T. Caillat. MRS Bull. 31, 224 (2006).

[12] S. LeBlanc. Sustain. Mater. and Technol. 1, 26 (2014).

[13] G.S. Nolas, J. Poon, M. Kanatzidis. MRS Bull. 31, 199 (2006).

[14] G. Tan, M. Ohta, M.G. Kanatzidis. Phil. Trans. A 377, 20180450 (2019).

[15] Г.Г. Гаджиев, Ш.М. Исмаилов, Х.Х. Абдулаев, М.М. Хамидов. 3.М. Омаров. ТВТ 39, 437 (2001).

[16] С.М. Лугуев, Н.В. Лугуева, В.В. Соколов. ФТТ 30, 873 (1988).

[17] C. Wood, A. Lockwood, J. Parker, A. Zoltan, D. Zoltan, L.R. Danielson, V. Raag. J. Appl. Phys. 58, 1542 (1985).

[18] С.М. Лугуев, Н.В. Лугуева, В.В. Соколов. Тезисы ХІІІ Межгос. семинара „Термоэлектрики и их применения“ 1 (2012).

[19] M. Ohta, S. Hirai. J. Elec. Mater. 38, 1287 (2009).

[20] M. Ohta, S. Hirai, T. Kuzuya. J. Elec. Mater. 40, 537 (2011).

[21] V.V. Bakovets, A.V. Sotnikov, A.Sh. Agazhanov, S.V. Stankus, E.V. Korotaev, D.P. Pishchur, A.I. Shkatulov. J. Am. Ceram. Soc. 101, 4773 (2018).

[22] С.М. Лугуев, Н.В. Лугуева, В.В. Соколов. ФТТ 42, 1013 (2000).

[23] А.В. Сотников, В.В. Баковец, А.Ш. Агажанов, С.В. Станкус, Д.П. Пищур, В.В. Соколов. ФТТ 60, 482 (2018).

[24] С.М. Лугуев, Н.В. Лугуева, В.В. Соколов. Теплофизика и аэромеханика 19, 375 (2012).

[25] H.S. Nalwa. Nanostructured materials and Nanotechnology. (2001). 834 p.

[26] А.И. Гусев. Наноматериалы, наноструктуры, нанотехнологии. Физматлит, М. (2005). 416 с.

[27] В.В. Баковец, Л.Н. Трушникова, И.В. Корольков, П.Е. Плюснин, И.П. Долговесова, Т.Д. Пивоварова, Н.И. Алферова. ЖОХ 83, 1 (2013). 
[28] M. Ohta, S. Hirai, H. Kato, V.V. Sokolov, V.V. Bakovets. Mater. Trans. 50, 1885 (2009).

[29] Л.С. Чучалина, И.Г. Васильева, А.А. Камарзин, В.В. Соколов. ЖАХ 33, 190 (1978).

[30] Т.Г. Аркатова, Б.П. Жузе, М.Г. Карий, А.А. Камарзин, А.А. Кухарский, Б.А. Михайлов, А.И. Шелых. ФТТ 21, 3428 (1979).

[31] Б.А. Колесов, А.А. Камарзин, В.В. Соколов. ЖСХ 38, 655 (1997).

[32] D.S. Knight, W.B. White. Spectrochim. Acta 46, 381 (1990).

[33] Г.Г. Гаджиев, Ш.М. Исмаилов, М.А. Айдамиров, Г.Н. Дронова, П.П. Хохлачев, М-Р.М. Магомедов. Неорган. материалы 33, 404 (1997).

[34] V.V. Sokolov, V.V. Bakovetz, S.M. Luguev, N.V. Lugueva. Adv. Mater. Phys. Chem. 2, 25 (2012).

Редактор Ю.Э. Китаев 